\title{
DESAIN MERCHANDISE SEBAGAI PENUNJANG INFORMASI DAN PROMOSI SD ISLAM MIFTAHUL HUDA
}

\author{
Aris ${ }^{1}$ \\ Chris Syahnaz ${ }^{2}$ \\ Siti Mariah Ulfah ${ }^{3}$ \\ Dosen STMIK Raharja ${ }^{1}$ \\ STMIK Raharja Jurusan Teknik Informatika ${ }^{2,3}$ \\ Jl. Jendral Sudirman No. 40, Modernland, Kota Tangerang ${ }^{1,2,3}$ \\ E-mail: aris@ raharja.info, ${ }^{1}$,hris.syahnaz@raharja.info ${ }^{2}$,siti.mariah@raharja.info ${ }^{3}$
}

\begin{abstract}
ABSTRAK
Dalam era globalisasi ini peran Desain Komunikasi Visual tidak terlepas dari kehidupan manusia sehari-hari dan menjadi sangat penting. Manusia dengan kesibukan sehari-hari yang menyita sebagian besar waktunya, cenderung mengutamakan efektivitas. Efektivitas dapat dicapai dengan mengkomunikasikan suatu informasi atau pesan secara visual. Oleh karena itu, penggunaan media komunikasi visual sangat dibutuhkan dalam menginformasikan dan mempromosikan sebuah sekolah. Seperti halnya pada SD Islam Miftahul Huda yang saat ini membutuhkan media informasi dan promosi yang efektif, efisien, dan tepat sasaran salah satunya adalah berbentuk merchandise. Oleh sebab itu, akan dilakukan perancangan media promosi merchandise yang akan dijadikan pelengkap media promosi untuk meningkatkan jumlah siswa/siswi baru. Adapun metodologi yang digunakan yaitu analisa, observasi dan perancangan. Selain itu perancangan merchandise yang baru ini dirancang dengan aplikasi Adobe Illustrator dan Adobe Photoshop. Perancangan merchandise ini akan diimplementasikan yang dapat menjadi solusi dalam pemecahan masalah pada media promosi dan informasinya.
\end{abstract}

Kata kunci-informasi, promosi, merchandise

\begin{abstract}
In this era of globalization, the role of Visual Communication Design is inseparable from everyday human life and become very important. Man with the busyness of everyday life that take up most of the time, tend to prioritize effectiveness. Effectiveness can be achieved by communicating information or visual message. Therefore, the use of visual communication media is needed to inform and promote a school. As in SD Islam Miftahul Huda who currently require media information and promotion of effective, efficient, and targeted one of which is shaped merchandise. Therefore, it would be to design a media campaign merchandise that will be used as a complementary media campaign to increase the number of students / new student. The methodology used is the analysis, observation and design. Besides designing new merchandise is designed with Adobe Illustrator and Adobe Photoshop. The design of this merchandise will be implemented which can be a solution to problem solving in media promotion and information.
\end{abstract}

Keywords-information, promotions, merchandise 


\section{PENDAHULUAN}

Pemanfaatan media informasi dan promosi oleh suatu sekolah bertujuan untuk memudahkan pengenalan akan profil sekolah dan fasilitas yang diberikan. Salah satunya melalui media komunikasi visual berbentuk merchandise. Pengenalan profil sekolah dan fasilitas yang diberikan merupakan proses bisnis sekolah melalui promosi dan informasi, sehingga dapat memudahkan sekolah dikenal oleh calon siswa/siswi. Untuk itu dengan menggunakan media komunikasi visual berbentuk merchandise maka sekolah akan lebih menarik dalam menyampaikan informasi dan promosi fasilitas pendidikan yang di tawarkan.

SD Islam Miftahul Huda adalah salah satu sekolah dasar yang mempersiapkan, mengarahkan dan membentuk siswanya untuk tidak hanya berilmu pengetahuan yang luas, tetapi juga mempunyai wawasan serta dasar-dasar keagamaan yang tinggi. SD Islam Miftahul Huda membutuhkan media komunikasi visual berbentuk merchandise untuk memenuhi kebutuhan konsumen dalam memberikan kesan terbaik tentang fasilitas pendidikan yang diberikan SD Islam Miftahul. Adapun desain media merchandise yang dibutuhkan antara lain: Tote Bag, Payung, Mug, Pin Button, Sticker, Notebook, Jam Dinding Melalui desain komunikasi visual berbentuk merchandise ini dapat meningkatkan image positif bagi SD Islam Miftahul Huda untuk lebih menarik calon siswa/siswi baru.

\section{LANDASAN TEORI}

\section{Pengertian Informasi}

Menurut Lusyani dkk (2015:80) Informasi adalah hasil dari pengelolahan data dalam suatu bentuk yang lebih berguna dan lebih berarti bagi penerimanya untuk pengambilan keputusan.

\section{Pengertian Promosi}

Menurut Lusyani dkk (2015:80) Promosi adalah suatu bentuk komunikasi pemasaran. Yang dimaksud dengan komunikasi pemasaran adalah aktivitas pemasaran yang berusaha menyebarkan informasi, mempengaruhi atau membujuk dan mengingatkan pasar sasaran atas perusahaan dan produknya agar bersedia menerima dan loyal pada produk yang ditawarkan perusahaan yang bersangkutan.

\section{TINJAUAN LITERATUR}

Dalam penelitian ini dilakukan penelusuran beberapa referensi (literature review) terhadap penelitian-penelitian sebelumnya yaitu sebagai berikut:

1. Jurnal yang ditulis oleh Ginanjar Prihantoro 2014, berjudul "Perancangan Visual Merchandising Brand Mizone sebagai Media Promosi". Jurnal tersebut menjelaskan dengan dibuatnya visual merchandising yang dapat mencitrakan dan mempresentasikan brand Mizone, sehingga dapat membantu menarik minat konsumen khususnya di Giant Semanggi Jakarta.

2. Laporan skripsi yang ditulis Gita Mawarni 2016, berjudul "Perancangan Media Komunikasi Visual Sebagai Sarana Informasi dan Promosi Hotel Istana Nelayan". Dalam laporan tersebut menjelaskan bahwa belum adanya media komunikasi visual yang menarik, efektif dan dapat menunjang kegiatan informasi dan promosi pada hotel Istana Nelayan yang dapat menarik minat 
konsumen.

3. Jurnal yang ditulis oleh Vijar Maya Puspita Sari 2010, berjudul "Desain Komunikasi Visual Sebagai Strategi Perancangan Promosi Pariwisata Pantai Watukarung Kabupaten Pacitan". Jurnal tersebut menjelaskan tentang perancangan promosi wisata Watukarung Kabupaten Pacitan agar pantai Watukarung lebih dikenalmasyarakat luas sekaligus mempercepat protes komunikasi terhadap target sasaran.

4. Jurnal yang ditulis oleh Dewi Immaniar, Sudaryono, dan Dwi Ayu Ningrum berjudul "Enriching Media Merchandise Penunjang Promosi Studi Kasus Pada Book-Store". Jurnal tersebut menjelaskan bahwa PT. Times Prima membutuhkan tambahan jenis media penunjang promosi yang lebih variatif dan kreatif dari yang sudah ada, yang nantinya aka digunakan sebagai pelengkap media promosi dan sebagai pembaharuan data serta untuk memperkaya desain promosi guna menjaring minat promosi.

5. Laporan skripsi yang ditulis oleh Andrri Sukih berjudul "Perancangan Media Penunjang Sarana Program Promosi Pada SMP Birul Waliadain Batu Ceper Kota Tangerang”. Dalam laporan tersebut menjelaskan bahwa perancangan media yang diajukan di SMP Birrul Waliadain bertujuan perolehan calon siswa SMP Birrul Waliadain batu Ceper Kota Tangerang dapat selalu meningkat setiap tahunnya. Dalam upaya peningkatan efektifitas program promosi diusulkan lembaga sekolah tersebut mulai penerimaan siswa baru Tahun Ajaran 2016/2017 menggunakan untuk meningkatkan efektifitas program promosi agar media komunikasi visual salah satunya dalam bentuk merchandise.

\section{METODE PENELITIAN}

Dalam penelitian ini metode-metode yang digunakan adalah $\square$

a).Analisa Permasalahan berisi pembahasan mengenai permasalahan yang akan diangkat dari SD Islam Miftahul Huda. Dari hasil pembahasan tersebut dapat disimpulkan bahwa permasalahan yang ada saat ini adalah kurangnya media promosi seperti merchandise yang menarik, sehingga akan meningkatkan calon siswa/siswi baru.

b).Pengumpulan Data, dalam mengumpulkan data dilakukan beberapa metode yaitu metode Pengamatan Langsung (Observasi) adalah metode dengan melakukan tinjauan langsung ke SD Islam Miftahul Huda untuk mendapatkan data-data yang diperlukan dengan melakukan pengamatan secara langsung dan melaksanakan pencatatan sistematis. Metode Wawancara (Interview) adalah metode pengumpulan data yang dilakukan dengan cara melakukan proses wawancara (tanya jawab) secara lisan kepada stakeholder yaitu Ibu Wirdah Permata Sari, untuk mendapatkan datadata yang diperlukan dalam penelitian, Selain observasi dan pengumpulan data,dilakukan juga studi pustaka yaitu melakukan pengumpulan data dengan mempelajari buku-buku yang terkait dengan system penulisan dan mempelajari unsur-unsur objek yang sedang diteliti.

c).Analisa Perancangan Media, Pengolahan data atau informasi yang akan diangkat dan akan dianalisa, dengan menggunakan software dalam proses desain yaitu Adobe Photoshop dan Adobe Illustrator. 


\section{HASIL DAN PEMBAHASAN}

\section{Konsep Perancangan}

Dalam konsep perancangan media merchandise ini memiliki beberapa perencanaan, yaitu:

a) Perencanaan Media

Untuk menarik minat calon siswa/siswi baru melalui desain merchandise sebagai media penunjang promosi pada SD Islam Miftahul Huda, bentuk desain komunikasi visual yang diterapkan kedalam beberapa media cetak yang diimplementasikan kedalam media merchandise yang didalamnya terdapat unsur visualisasi logo, elemen desain, typography dan warna yang sesuai dengan SD Islam Miftahul Huda, sehingga terlihat menarik.

b) Perencanaan Pesan (Konsep Kreatif)

Konsep kreatif penelitian ini dituangkan ke dalam media promosi dengan sebuah ide kreatif berdasarkan data-data yang diperoleh dari SD Islam Miftahul Huda yang bernuansa islami, kemudian diolah menjadi sebuah rancangan yang menarik yang dilakukan pada setiap media sesuai dengan kebutuhan. Dalam setiap media merchandise, unsur warna, garis, dan tulisan harus berkesan balance pada perancangan ini terdapat logo symbol dan logotype berupa typography, agar menarik secara visualisasi serta dapat diterima oleh calon siswa/siswi baru.

c) Perencanaan Visual

Pada setiap desain diperlukan nuansa baru, ide-ide kreatif, bentuk visualilasi yang dibuat secara menarik dan terkesan islami serta perpaduan unsur warna sesuai dengan identitas SD Islam Miftahul Huda.

\section{Tujuan Kreatif Desain Media Komunikasi Visual}

Tujuan kreatif dilakukannya desain Merchandise SD Islam Miftahul Huda adalah untuk menarik dan memberikan kesan yang positif untuk calon siswa/siswi baru. Dengan konsep desain yang baru serta unsur kreatif yang ada didalam media merchandise diharapkan akan meningkatkan image sekolah dan meningkatkan jumlah siswa/siswi setiap tahunnya.

Adapun beberapa software yang digunakan dalam desain merchandise ini diantaranya:

a) Adobe Photoshop CS6

Adobe Photoshop CS6 merupakan program berbasis bitmap yang dapat membantu dan memberikan kemudahan bagi desainer dalam membuat aneka desain web. Dengan kemampuan yang dikatakan mendekati sempurna maka sangat membantu bagi para desainer web dalam menggunakan ide dan imajinasinya dalam menciptakan sebuah karya grafis secara lebih optimal. Desainer dapat mengolah foto, membuat kreasi button, dan membuat teks yang menarik. 


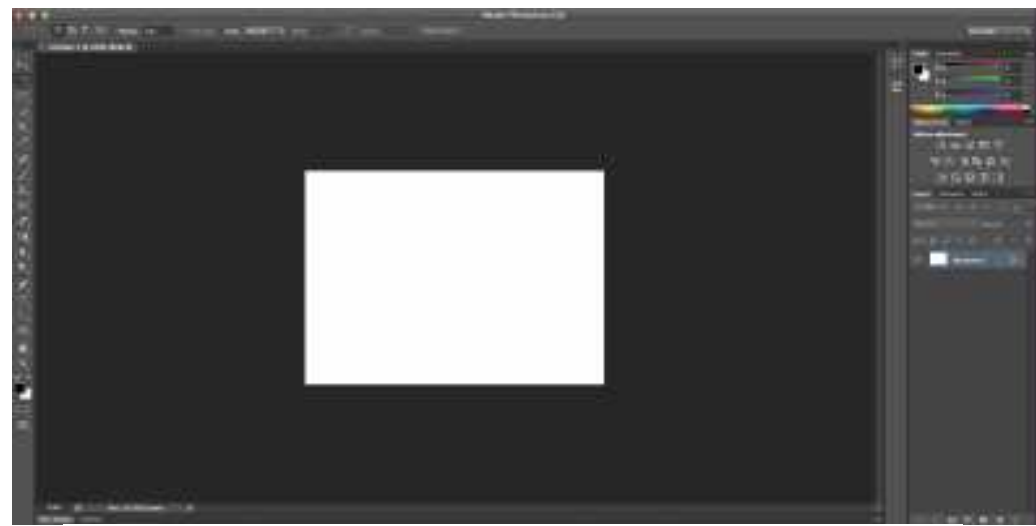

Gambar 1. Adobe Photoshop CS6

b) Adobe Illustrator CS6

Adobe Illustrator CS6 adalah software pengolah vektor dan gambar serta ilustrasi yang dapat digunakan untuk menciptakan suatu gambar imajinasi atau tokoh karakter.

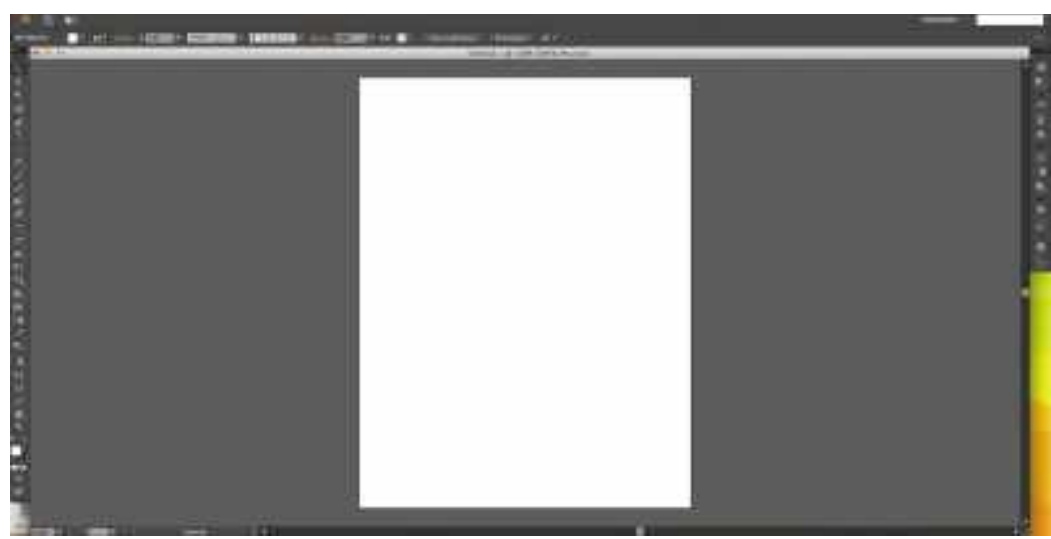

Gambar 2. Adobe Illustrator CS6

\section{Proses Desain}

\section{Layout Kasar}

layout kasar berupa kumpulan sketsa dari penuangan gagasan yang telah direncanakan namun masih dapat dievisi kembali dalam pembuatan desainnya dan dapat dikembangkan lagi. 

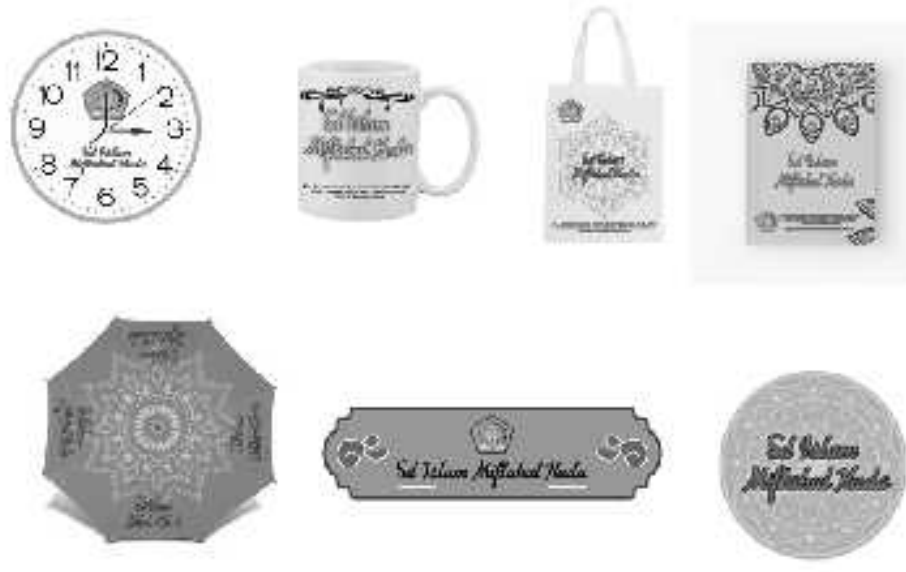

\section{Gambar 3. Layout Kasar}

Pada gambar 1 menampilkan layout kasar berbagai bentuk merchandise yang akan dirancang menggunakan software adobe photoshop dan adobe illustrator.

\section{Komprehensif}

komprehensif adalah tahapan layout yang dibuat dengan proses komputerisasi. Layout komprehensif juga merupakan layout yang sudah pasti, mulai dari gambar, warna dan susunan teksnya. Dalam tahap ini diperlukan pengerjaan yang cermat dan rapi.
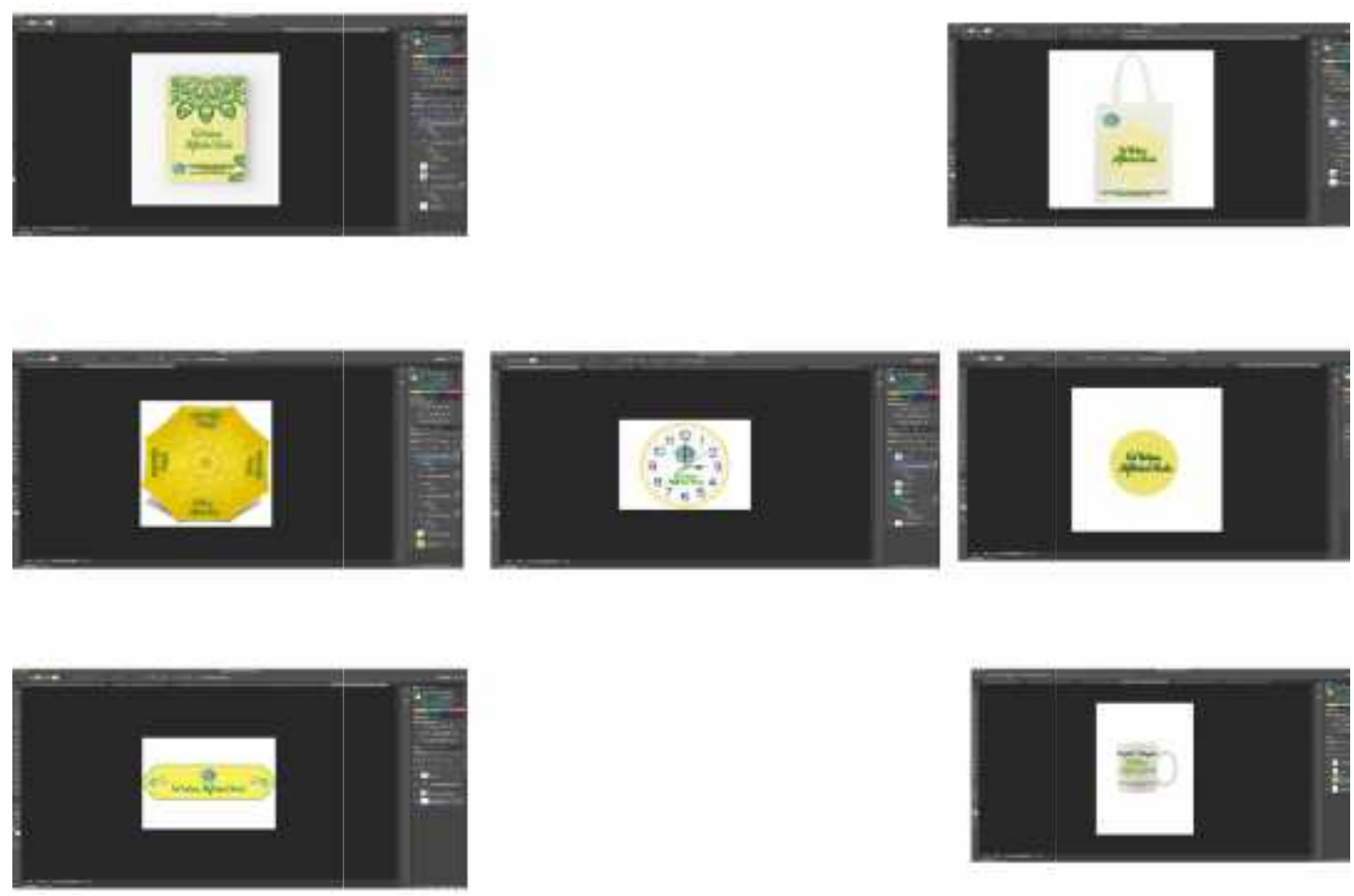

Gambar 4. Komprehensif 
Pada gambar 2 menampilkan layout komprehensif media merchandise di design menggunakan software Adobe Photoshop Cs6 dan Adobe Illustrator Cs6

3. Final Artwork

Final Artwork adalah tahapan akhir dari pengerjaan layout kasar dan komprehensif. Final Artwork juga dibutuhkan untuk tahapan produksi.

a) Final artwork Tote Bag

Berikut ini adalah hasi akhir merchandise tote bag SD Islam Miftahul Huda dengan logo dan juga dengan desain ornamen islam. Tote bag ini terbuat dari kanvas yang berukuran $25 \times 35 \mathrm{~cm}$

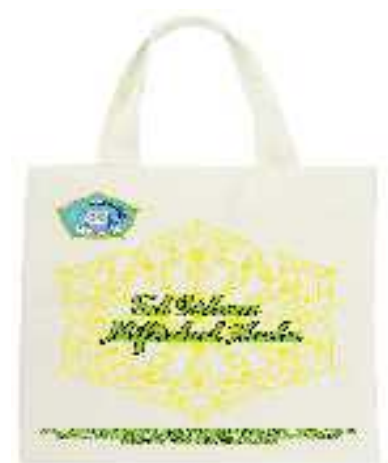

Gambar 5. Final Artwork Tote Bag

b) Final Artwork Jam Dinding

Final artwork desain jam dinding SD Islam Miftahul Huda dilengkapi logo dan nama sekolah dengan menggunakan material metal dan case material menggunakan plastic painted dengan ukuran diameter $30 \mathrm{~cm}$.

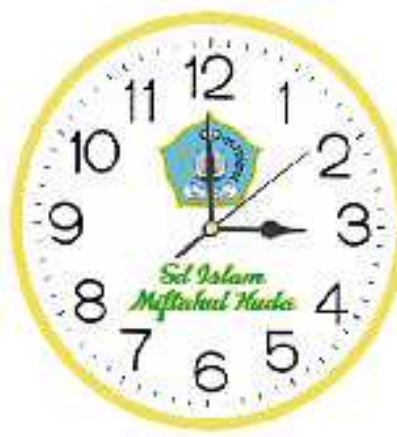

Gambar 6. Final Artwork Jam Dinding

c) Final Artwork Notebook

Final artwork desain notebook SD Islam Miftahul Huda dilengkapi dengan logo, alamat sekolah, alamat website sekolah dan juga diberikan ornamen islami dengan menggunakan material PVC synthetic Leather Cover, 60 sheets dengan ukuran $19 \times 13 \mathrm{~cm}$. 


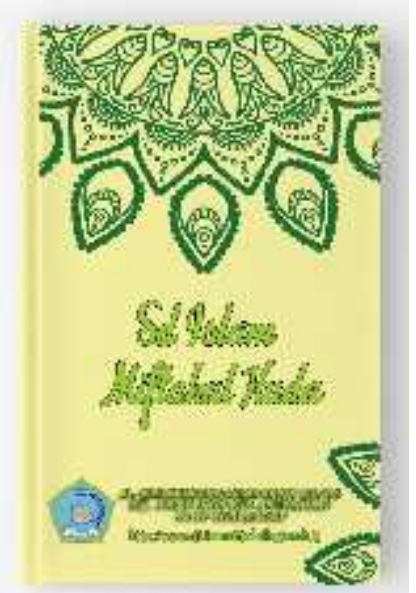

Gambar 7. Final Artwork Notebook

d) Final Artwork Payung

Final Artwork desain payung SD Islam Miftahul Huda ini diberikan ornamen Islam dan juga nama sekolah di beberapa sisi payung dengan type lipat 3, menggunakan material handle plastic, bahan polyeser, silver, kombinasi, dan nylon, dengan ukuran 21 inci.

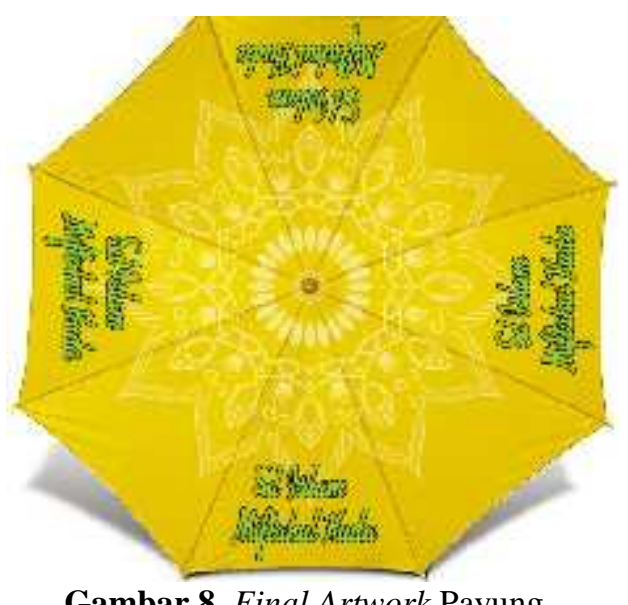

Gambar 8. Final Artwork Payung

e) Final Artwork Stiker

Final Artwork desain sticker diberi logo sekolah dan juga nama sekolah dengan menggunakan material chromo (bahan kertas licin) dengan ukuran 10 $\mathrm{x} 11,5 \mathrm{~cm}$.

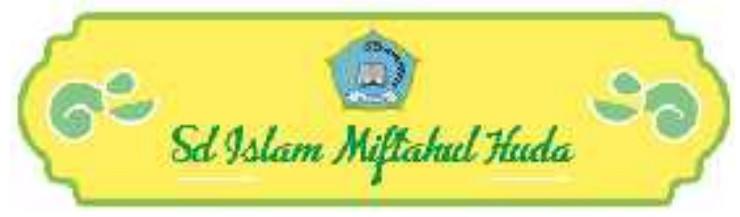

Gambar 9. Final Artwork Sticker

f) Final Artwork pin button

Final artwork desain pin button ini diberi ornamen islami dan juga nama sekolah dengan ukuran $7.5 \mathrm{~cm}$. 


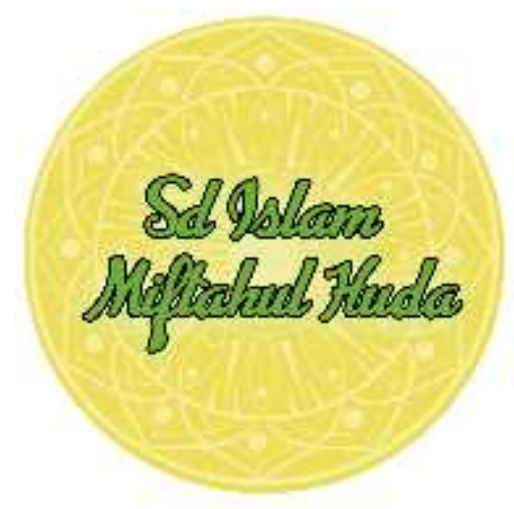

Gambar 10. Final Artwork Pin Button

g) Final Artwork Mug

Final artwork desain mug ini menggunakan material keramik dengan berat $400 \mathrm{~g}$ dan diberi ornamen islami sesuai dengan background sekolah SD Islam Miftahul Huda.

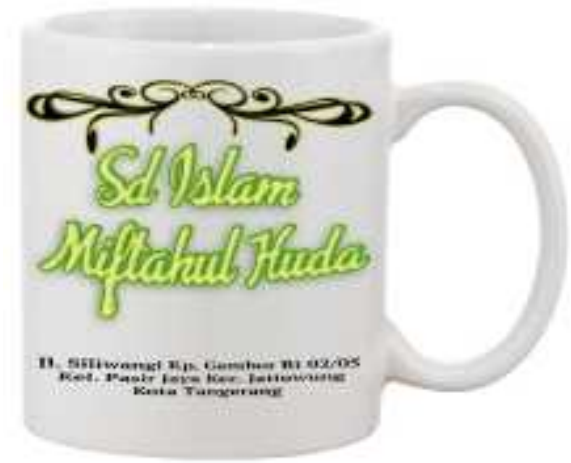

Gambar 11. Final Artwork Mug

\section{KESIMPULAN}

Untuk mempromosikan SD Islam Miftahul Huda dengan efektif, perlu diajukan perancangan media komunikasi visual berbentuk merchandise. Setiap pendaftar akan diberikan salah satu merchandise antara lain : Tote Bag, Payung, Mug, Pin Button, Sticker, Notebook, Jam Dinding. Dengan adanya perancangan media komunikasi visual berbentuk merchandise ini diharapkan dapat meningkatkan daya jual sekolah terhadap kepercayaan masyarakat khususnya orang tua murid, dalam mendaftarkan putra-putri mereka pada SD Islam Miftahul Huda .

\section{SARAN}

Perlu adanya peningkatan kualitas oleh SD Islam Miftahul Huda agar tidak ketinggalan perkembangan di bidang teknologi informasi. SD Islam Miftahul Huda juga harus berinovasi tentang kemajuan pengajaran dan selalu mengembangkan media-media promosi yang lebih menarik perhatian sebagai penunjang informasi dan promosi demi suksesnya pengembangan informasi SD Islam Miftahul Huda. 


\section{DAFTAR PUSTAKA}

[1] Hasan Bakrie, Muhammad. 2017. Laporan Kuliah Kerja Praktek Multimedia Audio Visual And Broadcasting Pada Sekolah SMK Bina Am Ma'mur, STMIK Raharja, Tangerang.

[2] Immaniar, Dewi. Sudaryono dan Dwi Ayu Ningrum. 2014. Enriching Media Merchandise Sarana Penunjang Promosi Studi Kasus Pada Book-Store. STMIK Raharja. Tangerang. http://goo.gl/91AxVi

[3] Mawarni, Gita. 2016. Pengembangan Media Komunikasi VISual Sebagai Sarana Informasi dan Promosi Hotel Istana Nelayan Tangerang. STMIK RAharja. Tangerang. http://goo.gl/XRCr9s

[3] Prihantoro, Ginanjar. 2014. Perancangan Visual Merchandising Brand Mizone sebagai Media Promosi: studi kasus Mall Giant Semanggi Jakarta. Salatiga: Universitas Kristen Satya Wacana. http://goo.gl/WgMFR5

[4] Puspita Sari, Vijar Maya. 2010. Desain Komunikasi Visual Sebagai Strategi Perancangan Promosi PAriwisata Pantai Watukarung Kabupaten Pacitan. Universitas Sebelas Maret Surakarta, Surakarta. http://goo.gl/F0MHbL

[5] Sukih, Andri. 2016. Perancangan Media Sarana Penunjang Program Promosi Pada SMP Birul Walidain Batu Ceper Kota Tangerang. STMIK Raharja, Tangerang. http://goo.gl/J4Eue4

[6] Sunarya, Lusyani dkk. 2015. Keefektifan Media komunikasi Visual Sebagai Penunjang Promosi pada Perguruan Tinggi Raharja. Tangerang : CCIT Journal STMIK Raharja. 